\title{
Imperatives and Trade-Offs for the Humanitarian Designer: Off-Grid Energy for Humanitarian Relief
}

\author{
Brita Fladvad Nielsen ${ }^{1}$ \\ ${ }^{1}$ Norwegian University of Science and Technology (NTNU), Norway \\ Correspondence: Brita Fladvad Nielsen, Department of Product Design, Norwegian University of Science and \\ Technology (NTNU), Norway. E-mail: brita.nielsen@ntnu.no
}

Received: December 11, $2013 \quad$ Accepted: February 11, $2014 \quad$ Online Published: February 19, 2014
$\begin{aligned} & \text { doi:10.5539/jsd.v7n2p15 } \\ & \text { URL: http://dx.doi.org/10.5539/jsd.v7n2p15 }\end{aligned}$

\begin{abstract}
This article will guide designers who hope to work in the unpredictable area of humanitarian relief. Conflicting interests among stakeholders is a key element of this unpredictability. Conflicting interests in the "humanitarian market" create significant barriers to the satisfactory implementation new designs. For this study, off-grid energy devices are identified as one of the most important devices, with significant room for improvement. Scarce resources, health issues and damaging ecological impacts make current energy sources untenable. The ideal design of off-grid energy devices must ideally be one that is sustainable, does not risk the health of the end-users, and provide jobs for the surrounding host communities. For this research, I interviewed product designers and humanitarian customers in order to understand the dilemmas inherent in this market. Findings revealed that a major barrier to successful design is the short-term focused humanitarian stakeholder system. Participants suggested trade-offs that can balance short term objectives with long term, triple bottom line, sustainable development goals in this dynamic environment.
\end{abstract}

Keywords: design process, refugee camps, off-grid energy, sustainable development, humanitarian design

\section{Introduction}

"Humanitarian aid", as realized within refugee camps, is conceived of as a short-term solution for people "temporarily" displaced by conflict or natural disaster (OECD, 2001). This "temporary" situation averages 17 years for the typical person residing in a refugee camp (UNHCR, 2003). This results in refugee populations being dependent on aid much longer than anticipated. This problem is especially acute in Sub-Saharan Africa, where the presence of hundreds of thousands of refugees living in relatively small, and often resource scarce areas, damages the ecological sustainability of the surrounding land. The introduction of technology into a development setting, requires a special focus on end-user acceptance (URD, 2011; Lyytinen, 2009). The designer must work with the end-user to create a user-centred design process. Currently, the end-user is not part of the information flow within the humanitarian market. This is due to the uni-directional nature of the humanitarian supply chain (Nielsen \& Santos, 2013b).

\subsection{Significance}

Off-grid energy devices represent a technical solution that can mitigate the damaging effects of refugee settlements. Off-grid energy devices refer to energy generating devices that do not require a connection to electric transmission grids. These devices lessen dependency on traditional non-renewable resources, such as diesel generators. Off-grid alternative energy devices (which already have been piloted in humanitarian refugee camps) include: solar panels, solar lanterns, solar cookers, fuel efficient stoves, ethanol stoves and kerosene stoves. Filling the need for sustainable lighting and cooking fuel sources is increasingly regarded as a way to provide additional educational opportunities, increased safety and improved health in areas with few resources (Sphere, 2004; Lyytinen, 2009).

In developing countries the use of wood fuel, traditional fuel for cooking and lighting in refugee camps, is one of the most prominent threats to the ecosystem (Carlson \& Clancy, 2004). Besides presenting a threat to the environment, its harvest often creates conflict between the host and refugee populations, and imposes high costs on humanitarian actors and end-users. Fuel pollution is directly responsible for two million deaths globally each year (Schwela, 1997; Smith et al., 2000). 


\subsection{Literature Review}

In architectural literature, a focus on long term sustainability in the early stages of emergencies has resulted in "transitional" and culturally sensitive "building back better" frameworks (Lyons, 2009; Kennedy et al., 2008) to guide shelter construction. Similar approaches are needed for product and service designers who focus on humanitarian relief.

In Sub-Saharan Africa, design for development approaches are based on appropriate technology (Carr, 1985) and Design for the Bottom of the Pyramid (Prahalad, 2006) describes methods which may guide the development of products, specifically for humanitarian relief. However, both approaches are dependent on creating sustainable markets and/or enterprises where individuals can generate an income. Their technological approaches are often dependent on the availability of skilled workers, and the availability of stable industrial capacities that are often missing in emergency situations. In humanitarian relief settings, where people are dependent on aid and remittances, the capacity of local industries is often too low to supply a camp with thousands of items (UNIDO, 2010). In addition, legal restrictions affect income generation in some emergency and refugee situations.

\subsubsection{Systems}

While (Oloruntoba \& Gray, 2006; Waters, 2010) originally described the system of humanitarian supply chain models in contrast to business supply chains, Mays et al. identified a mismatch between humanitarian and business systems and suggested a reinvention of the supply system. "Two systems meet, one of entrepreneurial and the other humanitarian values" (Mays, Racadio, \& Gugerty, 2012). In her view, inefficiency originates in the conflict between the humanitarian actor's mandate to protect and save lives, and the for-profit focus of the private sector. Moreover, recent evaluations of humanitarian emergency response suggest that the stakeholder environment is increasing in complexity, which is impacting the efficiency of interventions negatively (UNJIU, 2012). This complex stakeholder environment is an important characteristic of the humanitarian market. However, no research was found that described how this characteristic affects product development and innovation specifically for the off-grid energy sector.

\subsubsection{Business Models}

The literature found on business models in refugee settings, reveals specific challenges to implementing micro finance solutions. For example, the difficulty of achieving a sufficient pay-back rate of loans when people regard their stay in the camp as a temporary solution (Cavaglieri, 2008; Phillips, 2004). Refugees in most host countries do not have the right to earn an income, and are also restricted in terms of where and how far they can travel. If the relief situation has been ongoing for years, a dependency situation is created where the refugees are acclimated to receiving aid and will not want to spend money buying devices even if they have legally or illegally some. Another characteristic of the humanitarian market is that it can be regarded a quasi-market (Bartlett \& Le Grand, 1993) where the refugee has no say in what is being given to them. This will likely limit the potential of applying free market-based business models.

\subsubsection{Socio-Technical Relationships}

A limited number of research studies focusing on socio-technical relationships identify the negative social impacts of fuel scarcity (i.e. Lyytinen, 2009). For a person living in a refugee camp in an off-grid area, the issue of fuel scarcity represents numerous, often life threatening challenges (Lyytinen, 2009). According to the World Health Organization (WHO), 1.5 million people die every year from respiratory diseases related to smoke inhalation, most of them women and children. In refugee camps in sub-Saharan Africa, firewood and charcoal are the main fuel sources used for cooking. As deforested areas surrounding the camps expand, women, (who traditionally gather the fuel for cooking), must walk further from the camp to gather firewood, exposing them to assault and arrest. Existing research on technology acceptance in refugee camps, emphasizes the importance of contextually fitted solutions (URD, 2011).

\subsubsection{Technical Performance}

Research on technical performance highlights measurable impacts on air pollution and firewood consumption, when improved cooking stoves are used (Pennise et al., 2009; Al-Khatib et al., 2003). These technical studies are not context dependant, so studies focusing on technical performance in developing countries may also be applicable to refugee settings (Barnes et al., 1993; DM, 1995; Smith et al., 1993; Könemund \& Jargstorf, 2002; Brüderle, 2011).

This literature review has identified the limited technical performance studies, which provide insight into the environmental aspects of non-sustainable fuel use, as well as the socio-technical studies that focus on the negative social impacts of fuel scarcity. However, no studies were found that described the barriers and 
opportunities which impact product design and distribution within the humanitarian market. There is a documented need for research which aims to understand how, and if, it is possible to apply 'conventional' user centred and context driven design methods which can build off-grid sustainable energy access for the humanitarian market.

\subsection{Research Question}

The overarching, long-term goal of design for humanitarian markets, which informed this research study, is to minimize damage to the environment while creating socio-economic development opportunities (self-reliance) for the affected communities (Sphere, 2004). This goal is described in UNEPs initiative "Mainstreaming environment into humanitarian relief. It is also highlighted in policy documents from leading actors such as UNHCR, the Norwegian Refugee Council and Groupe URD which are frequently used to evaluate the sustainability of refugee camp activities.

The research question that guides this article is: Which choices can the product designer make in order to meet the conflicting agendas and challenges of the humanitarian market as described in (Nielsen \& Santos, 2013a; 2013b)?

\section{Method}

A qualitative method was chosen for this study because of the limited research examining the design challenges for designers working in the humanitarian market. This paper presents findings that relate to the "sustainability" of product design and technology introduction in refugee camps. These findings are part of a larger interview study, (Nielsen \& Santos, 2013a; 2013b) which examined the challenges of the humanitarian market on product design as described by the stakeholders.

The design challenges of the humanitarian market include understanding the role of product and service design within the 'humanitarian system', and how conflicting agendas can be balanced during the design process. This study regards the humanitarian system as the system of stakeholders relevant to product design within the 'humanitarian market'. This includes the people who handle the product from purchase to end-of-life as well as decision makers (both direct and indirect) who are involved in the product selection process.

\subsection{Objective}

The objective of this article is to suggest mechanisms or paths by which a designer can navigate within the status quo of the humanitarian market as described by the study participants.

\subsection{Participant Characteristics}

Table 1. Participants

\begin{tabular}{lll}
\hline Categories & Agencies & \# Participants \\
\hline $\begin{array}{l}\text { Humanitarian } \\
\text { (Non-governmental } \\
\text { organizations, }\end{array}$ & Norwegian Refugee Council (NRC) & \\
NGOs) & Head Office NRC Country staff & 3 \\
& NRC Field staff & 4 \\
& Best Net Europe (Aidex 2012) & 1 \\
& United Nations Humanitarian Commission & \\
& Refugees (UNHCR) Ethiopia & 1 \\
& Save the Children & 1 \\
& German Society for International Cooperation (GIZ) & 1 \\
& Ethiopia & 3 \\
Designers/ & Norwegian enterprises & 1 \\
product developers & UK enterprise & 1 \\
& U.S. enterprise & 1 \\
\hline Total & Dutch enterprise (Aidex 2012) & 17 \\
\hline
\end{tabular}


Representative 'experts' from both the supplier side and customer side of the 'humanitarian market', were recruited as participants (categorised as 'international enterprises' and 'humanitarian customers', respectively) (see Table 1). 'Experts' were recruited into the study if they represented an enterprise that developed products specific for humanitarian relief and/or a development market, with humanitarian NGOs as customers. Well-established NGOs were selected as participants if they were currently delivering services and purchasing products, including off-grid energy devices, for use in the field and on a global scale. A requirement for the humanitarian customer NGOs was that they were included in the Logistics Cluster. The Logistics Cluster is a network of emergency relief actors lead by the World Food Program. When an emergency occurs that requires global assistance, it is this network that manages the deployment of products.

\subsection{Sampling Procedures}

A precondition for the larger research project, of which this study is a part, is to explore the role of Norwegian industries within humanitarian relief. The Norwegian Refugee Council was identified as a good starting point due to its cooperation with Norwegian industries within the NOREPS network (Norway, 2014). The other NGOs were selected due to their long experience within humanitarian relief and strong role within the humanitarian Logistics Cluster, as well as recommendations from the NRC and the UNHCR. Their personnel directly responsible for technical product selection, implementation and follow-up were interviewed. The humanitarian customers were interviewed first. The enterprises were selected based on which products the humanitarian customers considered purchasing during the last five years. Enterprises' heads of research and development of new technologies for the humanitarian market were interviewed. As much as possible the interviews were conducted in person; however some interviews were conducted via video call (Skype).

\subsection{Interviews}

The interview focused on the use of technologies and energy needs in refugee camps with no access to an electrical grid. A narrative approach was used to elicit descriptions of how customers select and distribute technologies which can improve energy access. The customers were asked to explain their priorities, aims and product requirements. The enterprises were asked to describe a typical product design process and reflect on the different stages of their interaction with the humanitarian customer and the inputs that affected the product design. Further, they were asked to rate the attributes valued by humanitarian customers and reflect upon the effect of these priorities. The methodology has been thoroughly described in previous publications (Nielsen \& Santos, 2013a; 2013b).

\subsection{Data Analysis}

All interviews were recorded and transcribed as described in (Nielsen \& Santos, 2013a; Nielsen \& Santos, 2013b). The transcriptions of the interviews were again coded in relation to decision making during a product design and product-service system design process and in accordance with the over-arching goals of preventing harm on environment and socio-economic opportunities. The coding was completed in two phases: first by coding separate sentences, then by reading each interview and coding for the specific components of the research questions. Once all of the data was coded, similar patterns and themes were identified, and similar responses were grouped and linked to the relevant research questions.

\section{Results}

The interviews did not target any energy product specifically. However, all of the humanitarian customer participants explained that from an environmental perspective cooking fuel deserves the most attention. Fossil fuels, used for cooking, have a large negative impact on the environment surrounding humanitarian refugee camps. The participants explained that this concern is not receiving enough attention, because it is the most cost intensive.

\subsection{The 'Product' and the 'Product Designer' in the Humanitarian Market}

The "designer" was in this context addressed by the participants as the person responsible for the development of a product and/or a product-service-system. Therefore, the physical product and adjacent services or business models it has been designed for (or with) are considered as 'designed products' as a package and relevant for the discussion. The product developer frequently presents the product to the customer together with a suggestion for distribution, and some enterprises partner with an NGO and construct a business model that goes along with the product. According to them, it is normally the product developer's role to sell any model of self-reliant distribution together with his or her product/product-service-system (Baines et al., 2007). 


\subsection{The Indecisive Humanitarian Customer}

According to the enterprise customers, working with humanitarian customers is more challenging than working with conventional consumers, due to unclear and undefined requirement and closed decision making. Depending on expert insights proved to be expensive and the design had to be improved later in the process, at added cost, when meeting the 'real' needs. A question emerging from this is whether it would have been more cost efficient for the designer to explore the context themselves rather than depending on the experts. One company explained that they had been financed by the Norwegian government to develop design insights specifically for an NGO and therefore depended on the NGO to bring them to the field.

\subsection{The Design Process and End-User Access}

According to enterprise participants, a design process normally begins with conducting contextual end-user research. The purpose of this is for the enterprises to develop insights into the challenges concerning the individual's motivations, needs and preferences in addition to external factors relevant for the design. When designing for the humanitarian market however, this first research phase was commonly replaced with 'expert' input from the humanitarian customers. The designers included in one of these interviews explained to us that they had used input from 'experts' from NGOs to design their items. The dependence on expert input later proved insufficient to meet the contextual demands when the prototype was ready for testing. One designer had made attempts to meet with humanitarian organizations to retrieve end-user and customer requirements, but was met with the message that "we'll test it when it is ready" and no clear requirements. The organizations were willing to test for usability but did not have any clear demands or routines for monitoring and evaluating product implementation. During meetings the customers had provided input on logistical factors, that it had to be 'as cheap as possible' and 'robust' and small technical attributes such as "it must include a cell phone charger". The company also explained that they had allocated many resources and time in order to understand the market and the end-user through expert interviews, meetings with different organizations and so forth after the first design iteration without finding a customer or a suitable business model. The findings have indicated that the inaccessibility of the end-user affects the design process negatively and the cost of obtaining insights about the end-user is too high and not a priority of the humanitarian customer. In a design process, the designer has to take care to identify and include aspects pertaining to success criteria as early as possible in the process, since the cost of changes to the product will increase at later stages in the process (Ulrich \& Eppinger, 1995). The NGOs highlight the need for context specific products that ease introduction and user acceptance. However, organizations do not facilitate access to end users, which results in the enterprise having access to experts and expert users, but not to the "real needs" (Papanek \& Fuller, 1972) of the end-user, namely the refugee. "The beneficiaries of disaster assistance are not analogous to consumers, who (in theory) can exercise choice and choose an alternative supplier if the price and quality of a particular product are not appealing"(Mays, Racadio, \& Gugerty, 2012).

\subsection{Safety Concerns}

Safety was mentioned as a first priority in addition to cost reduction both by customers and enterprises. According to the customers, a humanitarian organization as well as a donor would suffer from knowing that emergency victims were injured due to any decision made by the NGO protecting them. According to both enterprises and customers, incidents where for example refugees were injured from gas explosions in relation to cooking, were fatal for their reputation as an organization. This also affects their choice of product and makes them reluctant to choose similar products in the future. According to customers and enterprises, this challenge is larger in the humanitarian market than other markets, as training is unsatisfactory and experience with using the product is limited. As for larger scale solar panels, some refugees steal parts of the equipment or modify the devices given to them, and products designers are asked to take this into account.

\subsection{Long-Term Concerns and Short-Term Funding}

The humanitarian customers explained that they have a twelve months and sometimes two year humanitarian budget cycle. For the enterprises, this was identified as a major challenge because it limits the quality of chosen products. Within the funding cycle of 12 months, donors wish to see the largest impact per donation. Since follow-up is unsatisfactory, and due to the NGOs wish to please the donor, emphasis is put on the number of people reached by a donation. Enterprises are aware of this tendency and therefore many enterprises move from developing robust products for off-grid energy access and onto cheaper, shorter lasting products. And in order to justify for example solar panel equipment instead of diesel generators, the enterprises explained that they are trying to advocate for that the UNHCR increases the budget cycle for energy equipment to at least 4 years. Also, the availability of the product (stock) is an issue. In order to deploy thousands of items at the onset of a disaster, 
or soon after, mass-produced items become a natural choice that conflicts with contextually fitted design objectives. Humanitarian organizations do not have the resources nor mandate to stay in an area long enough to make the assessments and retrieve knowledge about local capacities and resource availability. Humanitarian customer participants explained that they understand this as conflicting with their goal to achieve local industrial sustainability and to stimulate the production of contextually fitted solutions and ideas that originate in the local society.

\subsection{Product-Use Challenges Beyond Hand-Over}

According to the enterprises, there is no agreement about who's responsible for a deployed product after hand-over and therefore the possibility of improving a technology to fit the contextual challenges is smaller within the humanitarian market than in other conventional consumer market where feedback is frequently accessible. For them, the call from the humanitarian customers includes an idea that the product should be as self-reliant as possible, but the context is left out of the requirements which further challenges the design process and leaves the designer unable to know what types of conditions the product should perform under. As one NGO explained, products are for example stored in hot warehouses that deplete batteries, but this is something the producer was not made aware of during the development process. The design enterprise participants explained that the humanitarian clients either do not focus on environmental sustainability issues, or they do not have any clear indicators or requirements for the creation of a "sustainable product". From the manufacturer's viewpoint, access to the client's product requirements is the most common challenge they encounter when they develop a product for the humanitarian market.

Creating a sustainable cooking alternative depends on developing and distributing the right product and training both of refugee camp staff and women refugees, device maintenance, fuel distribution strategies and extensive follow-up. Both customers and enterprises raised this issue as a concern. For customers, their experience was that introducing cooking equipment was expensive and time-consuming for humanitarian staff. Also, cooking stoves needed to be robust. Together, these factors lead to these being too costly.

\subsection{Cradle-to-Cradle Concerns}

Life cycle assessment, material usage, end-of-life attributes, etc. was not mentioned by customers or partners. The introduction of fuel-efficient stoves requires an especially long acceptance phase, and therefore more human resources are required to provide follow-up and service. During interaction in relation to purchase between suppliers and customers of renewable energy products, issues such as material use, energy resources or end-of-life scenarios are not significantly raised according to the technology developers. Camp managers explain this focus by pointing to issues such as two year budget limits and legal frameworks, NGOs implicate product donors for not requiring follow-up, while enterprises feel overwhelmed by ever changing and considerable demands as well as difficulties creating a sustainable business model within a market based on donations. The complexities of the humanitarian market prove difficult to manage and relate to so both developer and customer sticks to the simple and manageable factors that are to bring down cost and ensure availability and donor funding. One enterprise, when asked if end-of-life is a concern, said bluntly that "I frankly cannot think about that, I have my hands full trying to get these products out there". In addition, the undefined time frame as well as undefined responsibilities (NRC, 2008), for example for waste management, or the lack of recycling facilities prevent a holistic cradle-to-cradle approach. Both NGOs interviewed and NRC confirms that there are not enough resources or procedures available for following up a product after it has been distributed.

\section{Discussion}

A list of choices has been extracted from the explanations of challenges to the effect on long term self-reliance objectives given by customers and enterprises. The discussion reflects upon which choices the designer may take in order to meet these.

\subsection{Design Imperative}

\subsubsection{Design Imperative 1: 'Do No Harm'}

A product as well as the service it depends upon must avoid creating dangerous situations even when there is minimal supervision, training and maintenance available in the field. Safety is an over-arching requirement of all products, while the others are balanced against each other. Designing for safety, also includes knowing that the product might be modified or used in an unintended way. In the humanitarian setting, many end-users may be unfamiliar with technology one designs and introduces, and may be illiterate. One way of designing for safety in this context can also be to develop the product so that a part will break early on due to tear and wear, so that the end-user has to turn it in for repair before more important parts of the product are worn out. This has been 
referred to by Amy Smith at dLab as "design for failure" (Vechakul, 2005). A do-no-harm approach however goes beyond the actual user-product relationship and into the discussion of dependency and socio-economic opportunities. A product designed for humanitarian relief should:

- Not have a negative effect on the surrounding eco system by adding waste that cannot be handled by the local waste management systems.

- Avoid replacing already excising and functioning products and product-service systems relevant to sustain local self-reliance and resilience

\subsubsection{Design Imperative 2: Intuitive Design}

The ideal design for a relief situation would be one that is so simple and intuitive that it minimises the risk of unintended use and is honest in its designed performance. For example, designing so that the product or the packaging clearly indicates how it is used and stored. This may be relevant for any design, however in this context it is particularly challenging due to unpredictability regarding language, literacy or educational levels. While recent product design for conventional markets emphasize design for 'expert users' in order to foresee future technology scenarios, design for humanitarian markets should focus on simplifying and adapting to general but predictable user patterns. After all, the end-user is not in a position to select another product that fits better with her or his preferences or skill-level. The product will also most likely shift hands and be used by both staff and emergency affected. Manufacturing must also be considered in this simplicity. Increasingly, tests and authorization is required in order for a product to be selected for humanitarian interventions and it is therefore an imperative for a designer to be honest about the technical performance and design a product so it will be used as intended. Intuitive design however depends upon an expansion of knowledge of the end-user behaviour (Hassenzahl, 2005) which again rely on contextual design efforts and feedback.

\subsection{Design Trade-Offs}

The following design trade-offs are strongly related to the overarching challenge within the humanitarian market; the relationship between short-term interventions and longer term development impact. The main objective of a humanitarian intervention is to protect and save lives, while the objective of long-term development is to create self-reliance for the affected population(s). A design can be put within the sphere of short-term objectives where minimising damage and saving lives is of high priority or within a sphere where longer-term development objectives are included.

\subsubsection{Design Trade-Off 1: Local Capacity Building vs. Low Cost}

Customer participants asked for solutions where bringing down cost does not jeopardize environmental sustainability. One possible approach could be to evaluate the strategy based on the type and phase of emergency and resources in the field. In a large emergency, mass produced cheap items could be designed with a service system dependent on local business development. A more chronic emergency situations or transitional phases where the communities are moving into a post-conflict scenario, one could expect that designers travel to the context in order to link local industrial capacities in a product service-systems approach. The latter would require more time and engagement with local actors. Many of the current product systems solutions for sustainable lighting base themselves on the assumption that the recipient can set up a small business and sell or rent out devices to the community. A product service-system solution requires insights into the local context and especially the rights of refugees in each context to build enterprises. In many countries, the refugees are not allowed to earn an income or leave the camp, which might mean that the designers are required to also engage local host communities in the designs. This is also likely to increase the benefits of a product or service.

4.2.2 Design Trade-off 2: Direct-Market Stimulation and Shorter Lifespans vs. Donated Items With Longer Life Spans

Many companies see the development of suitable business models as an expansion of their product and product service system and a solution to lining short term donations with long term concerns of the customer and host government. This can overlap with trade-off number one depending on the product type. While solar-lanterns are likely to be enter these markets from Asian countries, sub-Saharan industry are ready for producing local stove designs. Designing sustainable business models or product service systems based on lower cost items would be a competitive advantage but will be weighed against maintenance-free imported solutions that can protect the environment faster. This again depends on the resources available in the context and the urgency of bringing in biodiversity saving solutions. Distributing high quality items could mean that the refugee population may become dependent on donations. This could hamper the building of an income gathering, and sustainable direct 
market at a later stage. On the other hand, a foreign produced ethanol stove may be safer, live longer and over a period of time or with functional payment schemes be an affordable solution.

\subsubsection{Design Trade-Off 3: Designing in or Out of Context}

If a designer is designing a product that depends on contextually dependent resources, such as fuel, it is more likely that your item will be accepted by the end-user community if it adds a benefit also for the local partners. This would require a presence in the context by the designer in order to perfection the design. Also, items such as stoves that already have a cultural meaning in most communities will require more insights into habits than a newly introduced item such as a lamp. Since smaller companies consider the research and follow-up necessary to develop these concepts too expensive, another option could be that smaller enterprises offering solar lanterns etc. team up with larger companies with longer term customer relationships and suppliers of organizational equipment such as schools, hospitals and other shelter solutions. This will also provide them with improved and continuous opportunities for end-user feedback. Humanitarian organizations are reluctant to facilitate access to relief situations due to ethical and practical concerns (Jacobsen \& Landau, 2003), but an alternative could be to conduct the end-user research among the host population.

\subsubsection{Design Trade-Off 4: Design for Lifespan, Reuse or Local Recycling vs. Design for Return}

In humanitarian settings in low-income countries, most items are, according to NRC and UNCHR, reused. As long as an item can be picked apart, it will be taken apart and mended or used to create something else. According to the respondents in the survey, the humanitarian supply chain and deliverers of items in humanitarian relief locations do currently not include return of items from the location they deliver products to. For batteries or other toxic items, a requirement for designers could be that they suggest through their design ways to return toxic waste in already existing systems, either in the local context or together with the humanitarian system.

\subsubsection{Design Trade-off 5: Design Items that Encourage Impact Measurement vs. Service-Adding}

According to the participants, certain benefits of introducing stoves or lamps have been difficult to measure. Issues that are difficult to measure can be to which extent solar lights increase safety in a refugee camp or whether women or children have increased educational opportunities due to the efficiency of a cooking solution. One way for product designers to affect this could be to introduce an easier way to evaluate or get feedback from an end-user or a local distributor. An example of a way to facilitate a feedback process could be to empower the end-user to report on the performance of the stove through an SMS or a missed call on a cell-phone. Another way could be to design a device so that once something is broken, an item that is easily replaceable must be changed and that this demands that the end-user delivers the item to the NGO or company and thereby must file an explanation of the failure and performance. Designing products with additional service-systems in the local context is another area worth exploring.

\section{Conclusion}

When developing a concept for the humanitarian market, a decision about how to approach conflicting stakeholder interests must be determined. Therefore, to exemplify for the designer what the findings might imply, these dilemmas have been presented as 'design imperatives' and 'design trade-offs'. The design imperatives refer to the issues highlighted by all customer participants which affect the reputation of a design within the humanitarian market. A trade-off refers to a situation that involves losing one quality or aspect of something, in return for gaining another quality or aspect. It often implies a decision to be made with full comprehension of both the upside and downside of a particular choice.

\section{Summary}

Designing for the humanitarian market implies continuous decision making while weighing the often diverse demands from multiple and changing stakeholders. The humanitarian customers want to increase the sustainability of their operations. Although, they are struggling to understand what this means in terms of requirements and how product introduction relates to sustainability objectives. Current dilemmas can be understood through six design trade-offs that take into account status-quo challenges and the limitations of the humanitarian supply chain.

Further design research in this area will benefit from an accumulation of concrete design projects which demonstrate the integration of sustainable use, follow-up and end-of-life perspectives into products and product service-systems. Design has a much greater role to play in humanitarian interventions. 
This study is limited to what can be affected through design. It does not estimate the effect on sustainability if humanitarian stakeholders and designers approached these challenges as a participatory effort. This remains an unresolved issue that should be undertaken by the wider research community.

\section{Acknowledgments}

I would like to thank NRC and especially Lisetta Trebbi and Jake Zarins, who welcomed my research project full heartedly when she was climate change advisor at NRC.

\section{References}

Al-Khatib, I. A., Ahmad Ju'ba, Nadine, K., Nihad, H., Nuha, H., \& Salwa, M. (2003). Impact of housing conditions on the health of the people at al-Ama'ri refugee camp in the West Bank of Palestine. International Journal of Environmental Health Research, 13(4), 315-326. http://dx.doi.org/10.1080/09603120310001616092

Baines, T. S., Howard, W. L., Steve, E., Andy, N., Richard, G., Joe, P., ... Ashutosh, T. (2007). State-of-the-art in product-service systems. Proceedings of the Institution of Mechanical Engineers, Part B: Journal of Engineering Manufacture, 221(10), 1543-1552. http://dx.doi.org/10.1243/09544054JEM858

Barnes, D. F., Openshaw, K., Smith, K. R., \& Plas, R. (1993). The design and diffusion of improved cooking stoves. The World Bank Research Observer, 8(2), 119. http://dx.doi.org/10.1093/wbro/8.2.119

Bartlett, W., \& Julian, L. G. (1993). The theory of quasi-markets. Macmillan Press.

Brüderle, A. (2011). Solar Lamps Field Test Uganda. Deutsche Gesellschaft für Internationale Zusammenarbeit (GIZ).

Carlson, G., \& Clancy, J. (2004). Gender and Energy for Sustainable Development: A Toolkit and Resource Guide.

Carr, M. (1985). The AT Reader: theory and practice in Appropriate Technology. Bootstrap Press.

Cavaglieri, S. (2008). Livelihoods \& Micro-finance in Refugee Camps.

DM, Kammen. (1995). Cookstoves for the developing world. Sci. Am. 273(1), 72. http://dx.doi.org/10.1038/scientificamerican0795-72

Hassenzahl, M. (2005). The thing and I: understanding the relationship between user and product. Funology, $31-42$.

Jacobsen, K., \& Loren, B. L. (2003). The dual imperative in refugee research: some methodological and ethical considerations in social science research on forced migration. Disasters, 27(3), 185-206. http://dx.doi.org/10.1111/1467-7717.00228

Kennedy, J., Joseph, A., Elizabeth, B., \& Ilan, K. (2008). The Meaning of 'Build Back Better': Evidence From Post - Tsunami Aceh and Sri Lanka. Journal of Contingencies and Crisis Management, 16(1), 24-36. http://dx.doi.org/10.1111/j.1468-5973.2008.00529.x

Könemund, T., \& Jargstorf, B. (2002). Commercial distribution of energy-saving stoves: the "Mirt stove" in Ethiopia. Entwicklung+ Ländlicher Raum, 36(2), 24-27.

Lyons, M. (2009). Building back better: the large-scale impact of small-scale approaches to reconstruction. World Development, 37(2), 385-398. http://dx.doi.org/10.1016/j.worlddev.2008.01.006

Lyytinen, E. (2009). New Issues in Refugee Research.

Mays, R. E., Robert, R., \& Mary, K. G. (2012). Competing Constraints: The Operational Mismatch between Business Logistics and Humanitarian Effectiveness. Paper read at Global Humanitarian Technology Conference (GHTC), 2012 IEEE.

Nielsen, B. F., \& ALR Santos. (2013a). Key Challenges of Product Development for humanitarian markets. In IEEE Global Humanitarian Technology Conference 2013, Silicon Valley.

Nielsen, B. F., \& Ana, L. R. S. (2013b). Designing for multiple stakeholder interests within the humanitarian market: the case of off-grid energy devices. International Journal of Learning and Change, 7(1), 49-67. http://dx.doi.org/10.1504/IJLC.2013.056496

Norway, Norwegian Ministry of Foreign Affairs / Innovation. (2014). NOREPS. MFA 2014 [cited 28.01.2014 2014]. Retrieved from http://www.noreps.no/

NRC. (2008). Position Document: Climate change, the environment and displacement. NRC. 
OECD. (2001). The DAC Guidelines, Poverty Reduction. OECD Paris.

Oloruntoba, R., \& Richard, G. (2006). Humanitarian aid: An agile supply chain? Supply Chain Management: An International Journal, 11(2), 115-120.

Papanek, V., \& Fuller, R. B. (1972). Design for the real world. Thames and Hudson.

Pennise, D., Simone, B., Seth, M. A., Wilhemina, Q., Firehiwot, M., Wubshet, T., \& Todd, W. (2009). Indoor air quality impacts of an improved wood stove in Ghana and an ethanol stove in Ethiopia. Energy for Sustainable Development, 13(2), 71-76. http://dx.doi.org/10.1016/j.esd.2009.04.003

Phillips, J. (2004). Challenges to the effective implementation of microfinance programmes in refugee settings. Forced Migration Review, 20, 5-8.

Prahalad, C. K. (2006). The Fortune at the Bottom of the Pyramid. Pearson Education India.

Schwela, D. (1997). Cooking smoke: a silent killer. People \& the planet/IPPF, UNFPA, IUCN, 6(3), 24.

Smith, G. S., Kun, H., \& Qiu, D. (1993). 100 million biomass stoves in China: How was it done? World Dev., 21(6), 941. http://dx.doi.org/10.1016/0305-750X(93)90053-C

Smith, K. R., Jonathan, M. S., Isabelle, R., \& Nigel, B. (2000). Indoor air pollution in developing countries and acute lower respiratory infections in children. Thorax, 55(6), 518-532. http://dx.doi.org/10.1136/thorax.55.6.518

Sphere, P. (2004). Humanitarian charter and minimum standards in disaster response. Oxfam.

Ulrich, K. T., \& Steven, D. E. (1995). Product design and development, 384. McGraw-Hill New York.

UNIDO. (2010). Discussion Paper Post-Crisis Industrial Rehabilitation and Reconstruction. In The Role of Industrial Development in the Achievement of the Millennium Development Goals.

UNJIU. (2012). Financing for Humanitarian Operations in the United Nations System. Geneva: United Nations Joint Inspection Unit.

URD, Groupe. (2011). Foyers améliorés au Tchad - Groupe URD.

Vechakul, J. (2005). Design of a bagasse charcoal briquette-making device for use in Haiti. Massachusetts Institute of Technology.

Waters, D. (2010). Global logistics: New directions in supply chain management. Kogan Page.

\section{Copyrights}

Copyright for this article is retained by the author(s), with first publication rights granted to the journal.

This is an open-access article distributed under the terms and conditions of the Creative Commons Attribution license (http://creativecommons.org/licenses/by/3.0/). 